\title{
SKIP controls flowering time via the alternative splicing of SEF pre-mRNA in Arabidopsis
}

\author{
Zhibo Cui ${ }^{\dagger}$, Aizi Tong ${ }^{\dagger}$, Yiqiong Huo, Zhiqiang Yan, Weiqi Yang, Xianli Yang and Xiao-Xue Wang ${ }^{*}$
}

\begin{abstract}
Background: Similar to other eukaryotes, splicing is emerging as an important process affecting development and stress tolerance in plants. Ski-interacting protein (SKIP), a splicing factor, is essential for circadian clock function and abiotic stress tolerance; however, the mechanisms whereby it regulates flowering time are unknown.

Results: In this study, we found that SKIP is required for the splicing of serrated leaves and early flowering (SEF) pre-messenger RNA (mRNA), which encodes a component of the ATP-dependent SWR1 chromatin remodeling complex (SWR1-C). Defects in the splicing of SEF pre-mRNA reduced H2A.Z enrichment at FLC, MAF4, and MAF5, suppressed the expression of these genes, and produced an early flowering phenotype in skip-1 plants.
\end{abstract}

Conclusions: Our findings indicate that SKIP regulates SWR1-C function via alternative splicing to control the floral transition in Arabidopsis thaliana.

Keywords: SKIP, Flowering time, Splicing factor, SEF, SWR1 complex

\section{Background}

Correct timing of the vegetative to reproductive phase transition, or floral transition, is essential for seed setting in higher plants. Studies have shown that factors involved in the floral transition, including the polymeraseassociated factor (PAF) and FRIGIDA (FRI) complexes, are integrated into such major pathways as the autonomous, vernalization, and photoperiod pathways $[1,2]$. FLOWERING LOCUS C (FLC) encodes a MCMI, agamous, deficiens and serum response family (MADS)-box transcription factor that acts as a central repressor of the floral transition, and five homologs, MADS AFFECTING FLOWERING (MAF) 1 to MAF5, exist in Arabidopsis (Arabidopsis thaliana) [3-5]. The repression of FLC by factors involved in the vernalization and autonomous pathways activates the expression of SUPPRESSOR OF CONSTANS 1 (SOC1) and FLOWERING LOCUS T (FT) to accelerate flowering. Vernalization, the acceleration of flowering by prolonged cold, epigenetically silences $F L C$ through the activity of polycomb repressive complex 2 ,

\footnotetext{
* Correspondence: wangxx@syau.edu.cn; xiaoxuewang6@163.com

* Correspondence: war

Rice Research Institute, Shenyang Agricultural University, Shenyang 110866, China
}

which deposits the repressive histone mark trimethylation cing of $F L C[7,8]$. The antisense transcript of $F L C$ affects the expression of the sense transcript, thereby influencing flowering time in Arabidopsis [9, 10].

In contrast, the PAF1 complex $[11,12]$, histone $2 \mathrm{~B}$ ubiquitination [13, 14], histone $3 \mathrm{~K} 4$ and K36 methyltransferase complexes [15-18], the ATP-dependent SWR1 chromatin remodeling complex (SWR1-C) [19-21], and FRI/ FRI-like genes (e.g., FRL1 and FRL2) [22, 23] are involved in the activation of $F L C$ to suppress the floral transition through chromatin modification or remodeling in Arabidopsis [2, 24]. The SWR1-C exchanges histone H2A for H2A.Z, producing variant nucleosomes. Photoperiod-independent early flowering 1 (PIE1), actin-related protein 6 (ARP6), and serrated leaves and early flowering (SEF) are components of the SWR1-C in Arabidopsis [24]. Mutations in PIE1, ARP6, and SEF confer early flowering phenotypes through the silencing of FLC, MAF4, and MAF5 expression [19, 20, 25]. The SWR1-C is required for H2A.Z deposition at FLC, MAF4, 
and MAF5 chromatin, which promotes transcription at these loci [21].

Precursor (pre)-messenger RNA (mRNA) splicing removes non-coding sequences (introns) from premRNAs and joins the coding sequences (exons) together to generate mature mRNAs; thus, splicing plays important roles in regulating gene expression and increasing protein diversity in eukaryotes [26]. Splicing is catalyzed by the spliceosome, a large flexible RNA-protein complex consisting of five small nuclear ribonucleoprotein particles (snRNPs) and more than 180 types of proteins [27]. In eukaryotes, two distinct spliceosomes catalyze pre-mRNA splicing: the major spliceosome (consisting of the snRNPs U1, U2, U5, and U4/U6) catalyzes the splicing of U2-type introns with $5^{\prime}$ splice site (5'ss) GT and 3' splice site (3'ss) AG sequences, while the minor spliceosome (consisting of the snRNPs U11, U12, U4atac, and U6atac) removes U12-type introns with AT-AC (5'ss-3'ss) termini [27, 28]. U12-type introns are rare, constituting less than $1 \%$ of all introns found in animals and plants $[28,29]$. Alternative splicing is a process whereby the coding and non-coding fragments of a gene are rearranged in various ways by the spliceosome at different splice sites, giving rise to several mRNA transcripts from a single pre-mRNA. This process regulates transcriptome and proteome diversity, and it controls gene expression and function [30,31]. As in other eukaryotes, splicing is emerging as an important process affecting plant development and tolerance to biotic or abiotic stress [31].

Genomic data show that about $42 \%$ of the introncontaining genes involved in development and biotic or abiotic stress responses in Arabidopsis are alternatively spliced [32, 33]. Alternative splicing of the tobacco (Nicotiana tabacum) $N$ gene contributes to the control of plant disease resistance [34]. Regulator of C-repeat binding factor (CBF) gene expression 1, a cold-inducible DEAD (Asp-Glu-Ala-Asp) box RNA helicase, plays essential roles in pre-mRNA splicing, especially under cold stress conditions [35]. Regulator of abscisic acid (ABA) response 1/ RNA-binding protein 25 , a proline-tryptophan-isoleucine (PWI) motif- and RNA recognition motif (RRM)-containing protein, affects $\mathrm{ABA}$ signaling by regulating the splicing of hypersensitive to $A B A 1$, a protein phosphatase $2 \mathrm{C}$ gene [36]. Alternative splicing is also an important mechanism in circadian clock regulation. Recently, Ski-interacting protein (SKIP), spliceosomal timekeeper locus 1, protein arginine methyltransferase 5 , and two CIRCADIAN CLOCK-ASSOCIATED 1 (CCA1) transcripts (CCA1 $\alpha$ and $C C A 1 \beta)$ were shown to regulate the circadian clock through alternative splicing in Arabidopsis [37-42]. Root initiation defective 1, a DEAH-box RNA helicase associated with pre-mRNA splicing, plays important roles in meristem maintenance, leaf morphogenesis, and root morphogenesis [43]. In addition, evidence indicates that alternative splicing is involved in flowering time control in Arabidopsis. Alternative splicing of FLOWERING TIME CONTROL LOCUS A (FCA) premRNA is involved in the control of the floral transition [44, 45]. RZ-1B and RZ-1C, nuclear-localized RNAbinding proteins, are involved in pre-mRNA splicing and flowering time control via interactions with serine/ arginine-rich (SR) proteins [46]. AtSF1, the homolog of mammalian splicing factor 1 in Arabidopsis, interacts with U2 snRNP auxiliary factor $65 \mathrm{a} / \mathrm{b}(\mathrm{U} 2 \mathrm{AF} 65 \mathrm{a} / \mathrm{b})$ and acts as a splicing factor to regulate flowering time and ABA signaling [47].

SKIP, an SNW domain-containing protein, is evolutionarily conserved, with close homologs in yeast and mammals. In mammals, SKIP (also termed SNW1 and NCoA62) plays important roles as a transcriptional coregulator and splicing factor $[48,49]$. SKIP specifically regulates the alternative splicing and expression of $p 21$ by interacting with the 3'ss recognition factor U2AF65 and recruiting it to $p 21 \mathrm{mRNA}$ in vivo [49]. In yeast, the SKIP homolog Prp45 is a component of the Prp19related complex (or nineteen complex), which functions as a splicing factor $[50,51]$. Weak mutations in prp 45 cause defects in the splicing of ACTIN and other genes, resulting in temperature-sensitive growth, while strong prp45 alleles are lethal $[50,52]$. OsSKIPa, which was able to rescue the defects in prp 45 mutant yeast, regulates cell viability and stress tolerance in rice (Oryza sativa) [53]. In Arabidopsis, SKIP regulates cytokinin-associated leaf growth [54]. SKIP expression is induced by salt, mannitol, and ABA. Overexpression of SKIP confers tolerance to abiotic stress. By contrast, the down-regulation of SKIP causes reduced tolerance to abiotic stress during germination. SKIP activated the transcription of a reporter gene in yeast, suggesting that it regulates gene expression as a transcription factor [55]. SKIP is a splicing factor that interacts physically with the plant-specific SR protein SR45 to regulate circadian clock function. The skip-1 mutation disrupts this clock, creating a lengthened clock period phenotype by altering the alternative splicing of PSEUDO-RESPONSE REGULATOR 7 (PRR7) and PRR9, two genes in the morning loop of the oscillator [40]. Genome-wide defects in splicing have been observed in skip-1 plants through RNA high-throughput sequencing, suggesting that SKIP is a splicing factor [40]. In addition to defects in the circadian clock, skip-1 plants show pleiotropic phenotypes, including early flowering. However, the molecular and biochemical mechanisms whereby SKIP represses the floral transition remain obscure.

In this study, we revealed that SKIP plays an essential role in regulating flowering time of Arabidopsis. SKIP was found to regulate the splicing of SEF pre-mRNA and suppress flowering by activating the expression of $F L C$. FLC expression was reduced in skip-1, leading to an early 
flowering phenotype under long-day (16 h of light/ $8 \mathrm{~h}$ of darkness, LD) and short-day ( $8 \mathrm{~h}$ of light/16 h of darkness, SD) conditions. SKIP was also required for the normal splicing of SEF pre-mRNA (which encodes a component of the SWR1-C) through direct binding. Splicing defects in $S E F$ were found to contribute to the early flowering phenotype of skip-1. Further, H2A.Z enrichment at FLC chromatin was reduced in skip-1. Our findings indicate a role for alternative splicing in regulating SWR1-C function to control the floral transition in Arabidopsis.

\section{Results}

SKIP is required for the floral transition and normal development in Arabidopsis

Previous studies showed that the skip-1 mutation lengthened the period of the circadian clock by impairing the alternative splicing of $P R R 7$ and $P R R 9$ in Arabidopsis [40]. The skip-1 mutation confers an early flowering phenotype under LD and SD conditions [40]; however, the underlying molecular mechanisms are unknown. A complementation test using SKIP genomic DNA and skip-1 plants revealed that the skip-1 mutation is responsible for the observed early flowering phenotype of the mutant (Fig. 1a-d; Additional file 1: Table S1 and Additional file 2: Table S2).

Pleiotropic phenotypes were observed in skip-1 compared to the wild type (WT), including reduced root growth (Fig. 1e and f; Additional file 3: Table S3); smaller sepals, petals, and flowers (Fig. 1h-j); shorter stigmas, stamens, and siliques (Fig. $1 \mathrm{k}-\mathrm{m}$ ). In the present study, we focused on dissecting the mechanisms whereby SKIP controls flowering time in Arabidopsis.

\section{SKIP activates the expression of FLC and its homologs to repress flowering}

Because the skip-1 mutation is insensitive to photoperiod, we examined the expression of CONSTANS (CO), a key regulator of photoperiodic flowering, in the skip-1 mutant [56]. CO expression in the skip-1 mutant was reduced or similar to that in WT Columbia (Col-0) plants under LD and SD conditions (Additional file 4: Figure S1a and b). To explore the molecular mechanisms whereby SKIP controls flowering time, we analyzed the expression of $F L C$ and its homologs MAF1 to MAF5, which are major suppressors of flowering, in skip-1. The expression of $F L C$, $M A F 1, M A F 4$, and MAF5 was significantly suppressed by the skip-1 mutation, leading to an early flowering phenotype under LD and SD conditions. Genomic DNA corresponding to the SKIP gene was able to recover the suppression of $F L C$ by the skip-1 mutation (Fig. 2a-d).

Down-regulation of $F L C$ is usually accompanied by the up-regulation of downstream genes to accelerate flowering. SOC1 and FT are known to accelerate the vegetative to reproductive phase transition in Arabidopsis downstream of FLC [2]. Twin sister of FT (TSF), an FT homolog, promotes the floral transition $[57,58]$. FD, a transcription factor, interacts with FT to promote the floral transition in the shoot apical meristem [59]. Both FT and FD are required for floral meristem formation [59, 60]. As expected, the skip-1 mutation activated the expression of SOC1, FT, and TSF, but not of $F D$, and it promoted flowering under LD and SD conditions (Fig. 2e-j; Additional file 4: Figure S1c). These results suggest that skip-1 represses the expression of $F L C$ and activates the expression of downstream flowering time integrators (e.g., SOC1, FT, and TSF) to accelerate flowering.

To test whether $F L C$ is genetically necessary for repression of the floral transition by SKIP, FLCdependent late flowering mutants, including FRI (Col0 background), fve, and flowering locus $k$ (flk), were crossed with skip-1 [22, 61-63]. The late flowering phenotypes of $F R I$, fve, and $f l k$ were dramatically suppressed by the skip-1 mutation (Fig. 3a; Additional file 5: Table S4).

To confirm that $F L C$ repression is the major mechanism that promotes flowering in skip-1, skip-1 plants were transformed with a 35S:FLC construct. Flowering time in the 35S:FLC transgenic lines was similar to that in WT plants because of the overexpression of $F L C$, indicating that $F L C$ was able to recover the early flowering phenotype of skip-1 (Fig. 3b and c; Additional file 6: Table S5 and Additional file 7: Table S6).

Together, these genetic and molecular data demonstrate that SKIP suppresses the floral transition in Arabidopsis in an $F L C$-dependent manner.

\section{SKIP promotes FLC expression by controlling the alternative splicing of SEF pre-mRNA}

We next investigated the mechanisms whereby SKIP regulates $F L C$ expression in detail. There are three possible explanations for the silencing of FLC by skip-1. First, the skip-1 mutation may cause the abnormal splicing of $F L C$ pre-mRNA and decrease the accumulation of functional FLC mRNA. Second, the skip-1 mutation may cause the overexpression of genes in the autonomous or vernalization pathway to reduce $F L C$ expression. Third, the skip-1 mutation may repress the expression of flowering time suppressors, including genes encoding members of the PAF1 complex, the SWR1-C, and so forth.

To explore the silencing mechanisms of FLC, MAF1, MAF4, and MAF5 in the skip-1 mutant, we first tested for defects in the splicing of FLC, MAF1, MAF4, and MAF5 pre-mRNA in the skip-1 mutant; except for $M A F 1$, no splicing defects were detected (Additional file 8: Figure S2a; Additional file 9: Figure S6b, d, and f). Next, we assessed the mRNA expression of genes in both the autonomous and vernalization pathways, including $F C A, F Y, F L K, F L D$, FPA, FVE, LD, VRN1, VRN2, and VIN3 [24]. The expression 

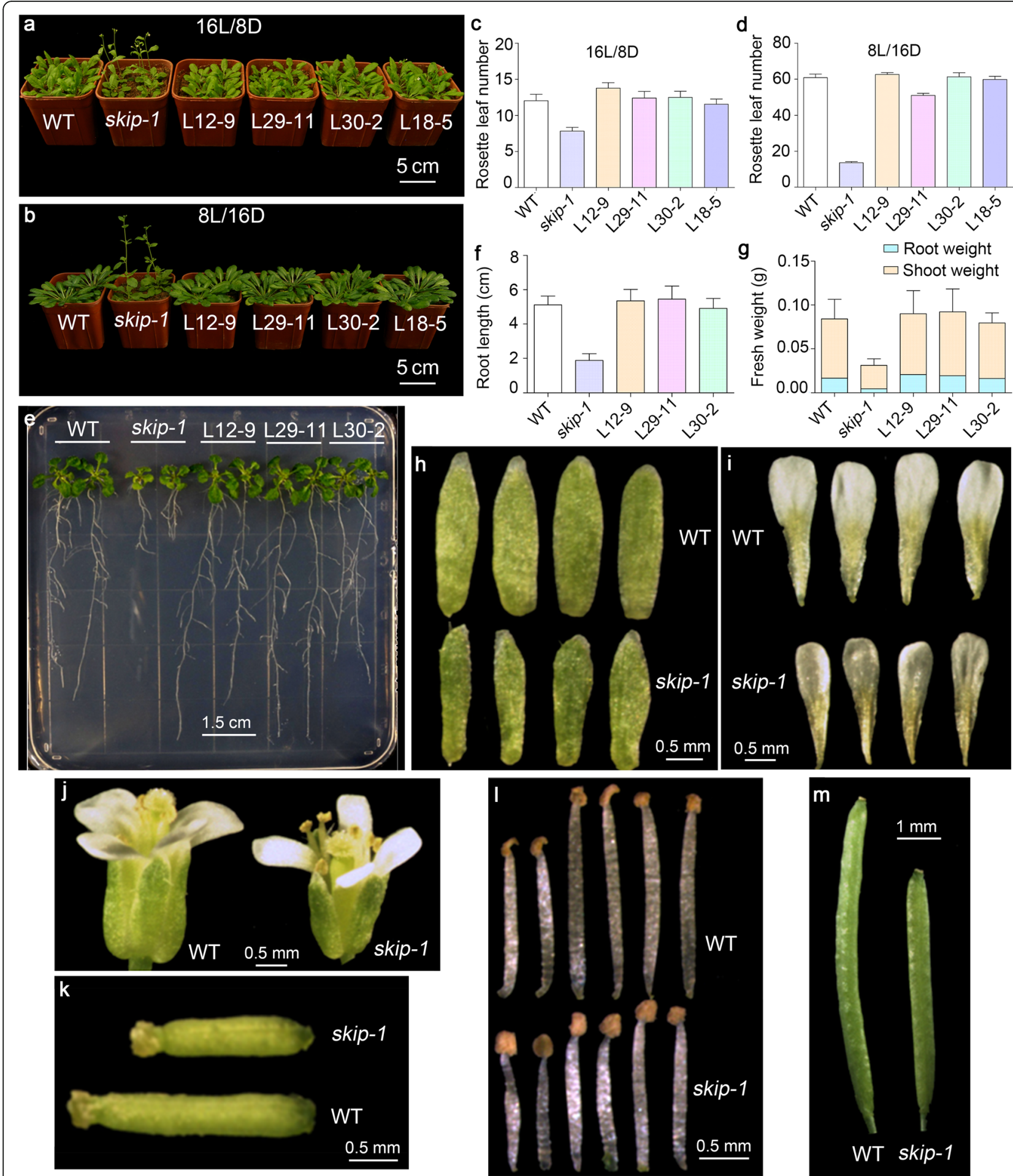

Fig. 1 Pleiotropic phenotypes of the skip-1 mutant. a-d Early flowering phenotype of skip-1 under LD (a, c) and SD (b, d) conditions. e, $\mathbf{f}$ Inhibition of root growth in skip-1 plants. $\mathbf{g}$ Shoot and root weights in skip-1 mutant plants. $\mathbf{h}-\mathbf{j}$ Comparison of sepal (h), petal (i), and flower (j) sizes in wild-type (WT) and skip-1 plants. k-m Comparison of stigma (k), stamen (I), and silique (m) lengths in WT and skip-1 plants. L12-9, L29-11, L30-2, and L18-5 are skip-1 transgenic lines harboring the PSKIP:SKIP genomic DNA construct. All data are given as the mean \pm standard deviation (s.d.) ( $n=31-36$ in $\mathbf{c}, n=11-12$ in $\mathbf{d}$, and $n=34-40$ in $\mathbf{f}$ ). Six pools of five seedlings are represented in $\mathbf{g}$. Scale bars are indicated in the images. 16L/8D: $16 \mathrm{~h}$ of light/8 h of darkness, 8L/16D: $8 \mathrm{~h}$ of light/16 $\mathrm{h}$ of darkness 


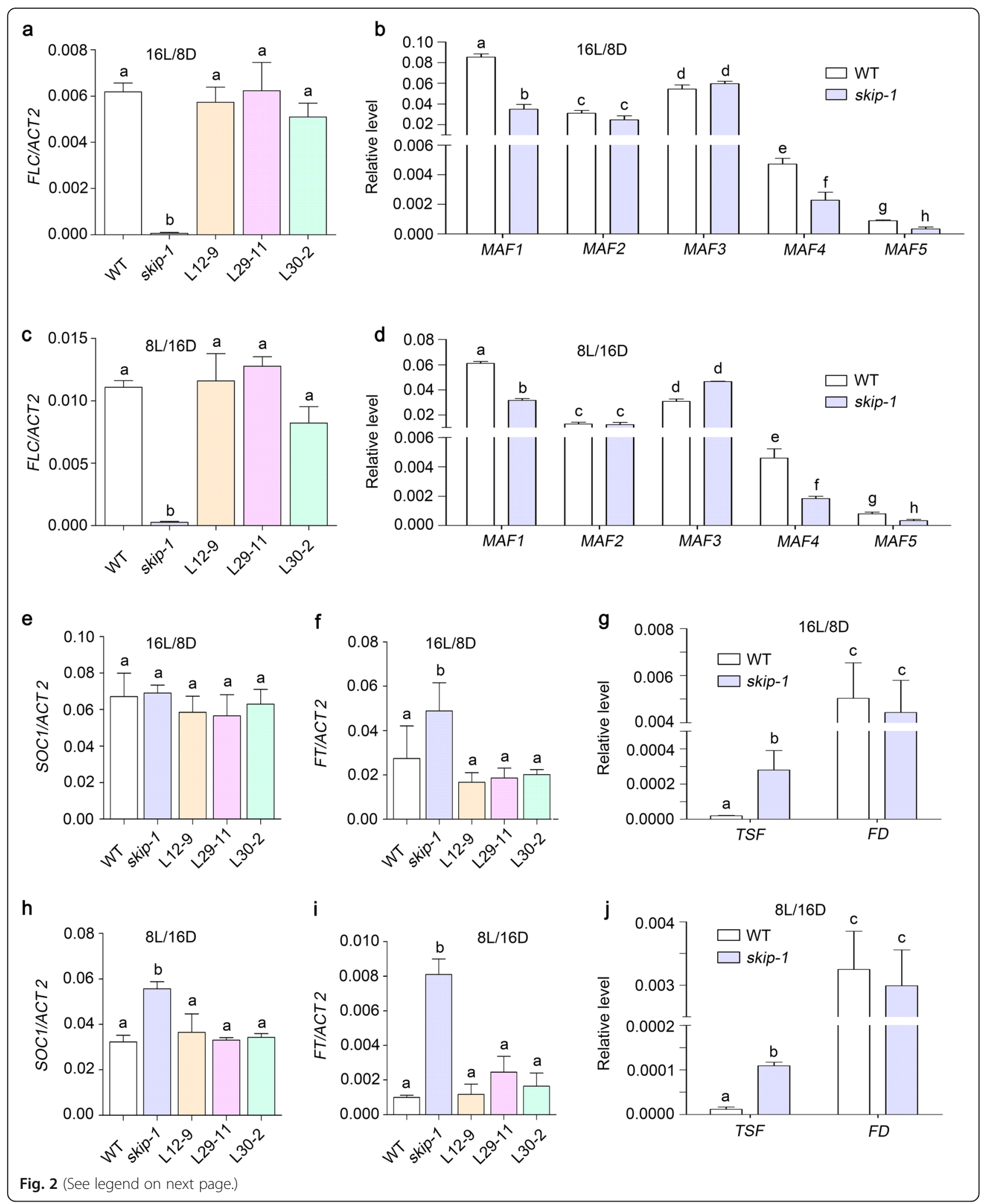


(See figure on previous page.)

Fig. 2 SKIP is required for the transcriptional activation of FLC and its homologs to repress flowering. Ten-day-old seedlings were used to examine flowering time-related gene expression by quantitative reverse transcription (qRT)-PCR. a, c FLC expression in WT plants, skip-1, and three of the skip-1 complemented transgenic lines described in Fig. 1 under LD (a) and SD (c) conditions. b, d MAF expression in WT and skip-1 plants under LD (b) and SD (d) conditions. e, $\mathbf{f}, \mathbf{h}, \mathbf{i}$ SOC1 and FT expression in WT plants, skip-1, and the three complemented transgenic lines under LD (e and $\mathbf{f}$ ) and SD (h, i) conditions. $\mathbf{g}$, j TSF and FD expression in WT and skip-1 plants under LD (g) and SD (j) conditions. ACTIN 2 (ACT2) was used as an endogenous control. The values are the mean \pm s.d. One-way analysis of variance (ANOVA; Tukey's multiple comparison test) was performed for data in $\mathbf{a}, \mathbf{c}, \mathbf{e}, \mathbf{f}, \mathbf{h}$, and $\mathbf{i}$, and two-tailed unpaired $t$ test was performed for data in $\mathbf{b}, \mathbf{d}, \mathbf{g}$, and $\mathbf{j}$. Statistically significant differences are indicated by different lowercase letters $(P<0.05)$. There are statistically significant differences between all non-identical letters

levels of these genes in skip-1 were similar to those in WT plants, suggesting that the skip-1 mutation does not silence $F L C$ by enhancing the expression of these genes (Additional file 8: Figure S2b and c). Finally, we analyzed the expression of floral suppressors, which were chosen according to a review [24]. Our results revealed aberrant alternative splicing and reduced levels of mature SEF mRNA, which encodes a component of the SWR1-C (Additional file 8: Figure S2d).
The expression and abnormal alternative splicing of SEF caused by the skip-1 mutation were confirmed by reverse transcription-PCR (RT-PCR) and quantitative reverse transcription-PCR (qRT-PCR), respectively (Fig. 4; Additional file 10: Figure S3). Elevated accumulation of alternatively spliced $S E F$ isoforms, including those showing intron retention, compared to the WT was detected in skip-1 (Fig. 4). However, the level of mature SEF mRNA encoding functional SEF protein was reduced by
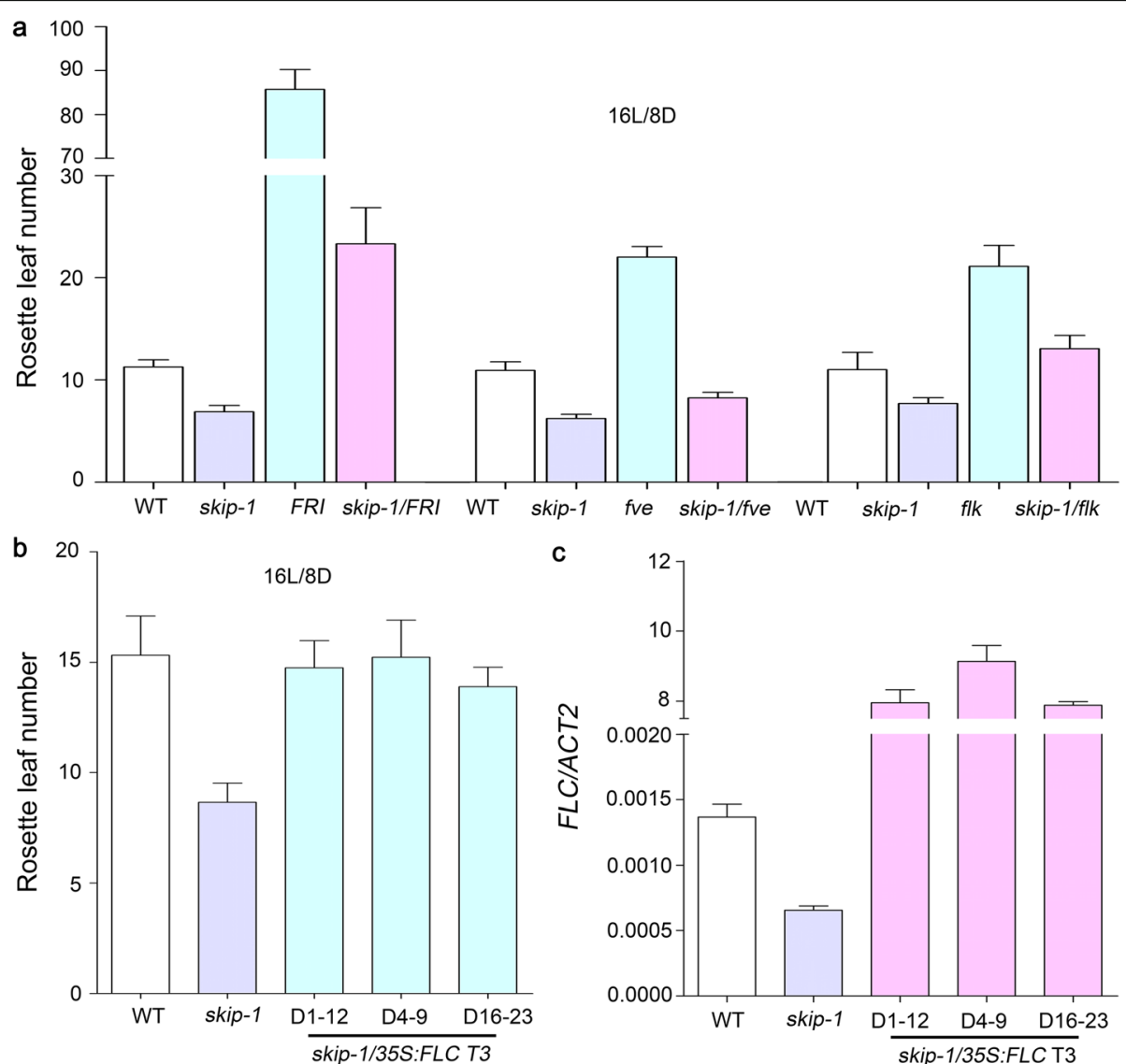

Fig. 3 Flowering time in skip-1/FRl, skip-1/fve, and skip-1/flk double mutants, and in skip-1 transgenic lines overexpressing FLC. a Rosette leaf number in WT, skip-1, skip-1/FRI, skip-1/fve, and skip-1/ffk plants under LD conditions. b Rosette leaf number in WT plants, skip-1, and three skip-1 transgenic lines (D1-12, D4-9, and D16-23) transformed with the 35S:FLC construct under LD conditions. The data are the mean \pm s.d. $(n=12-27$ in a; $n=18-23$ in b). c FLC expression as measured by qRT-PCR in WT plants, skip-1, and skip-1 transgenic lines carrying the 35S:FLC construct. ACT2 was used as an endogenous control. Three technical replicates were performed. The values are the mean \pm s.d. 


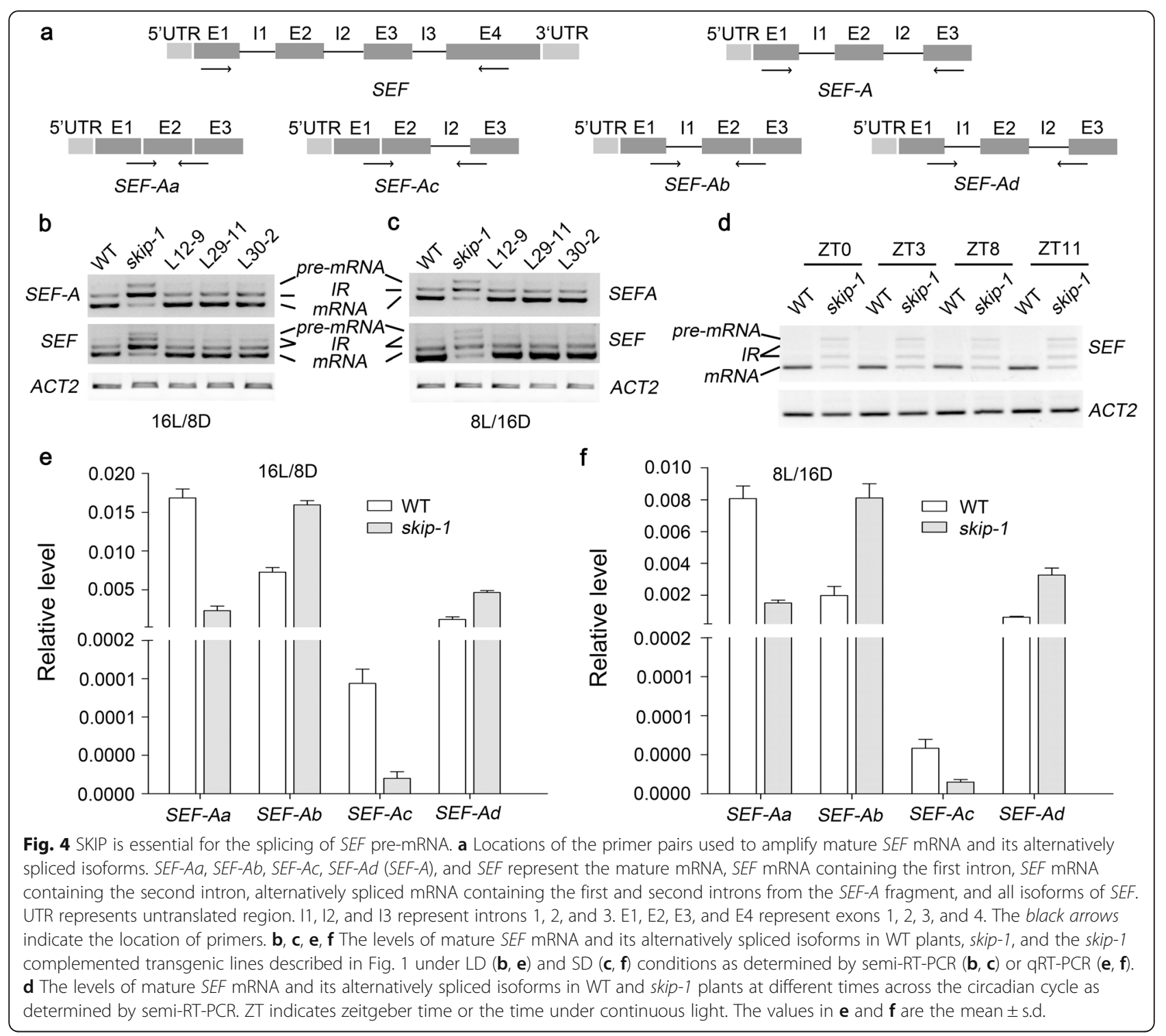

skip-1 (Fig. 4; Additional file 10: Figure S3). SEF has been characterized as a suppressor of flowering time and an SWR1-C component [20]. Therefore, we hypothesized that the down-regulation of $F L C$ in skip-1 mutants is caused by the abnormal splicing of SEF pre-mRNA.

To test this hypothesis, we generated three SEF complementary DNA (cDNA) constructs: one carrying the fulllength $S E F$ coding sequence (CDS), the second carrying the CDS plus the first intron (WT SEF IR, $\left.w t S E F_{I R}\right)$, and the third carrying the CDS plus a mutated version of the first intron (mutated $S E F_{I R}, m S E F_{I R}$ ), driven by the $35 S$ promoter. The 35S:wtSEF IR and 35S:mSEF $F_{I R}$ constructs were identical except for the 5'ss and 3'ss in the first intron, which were mutated in $m S E F_{I R}$ to produce a transcript that included the first intron (Fig. 5a). All three constructs were transformed into sef-2 plants [20].
As expected, RT-PCR showed that, unlike $w t S E F_{I R}$, which was efficiently spliced, $m S E F_{I R}$ plants accumulated unspliced $S E F_{I R}$ transcripts, which mimicked the large transcript in skip-1 mutant plants (Fig. 5b-d).

Transgenic plants expressing full-length SEF cDNA and $w t S E F_{I R}$, but not $m S E F_{I R}$, partially rescued the early flowering phenotype of $s e f-2$, indicating that $w t S E F_{I R}$ has a similar function to full-length $S E F$ cDNA. In contrast, the unspliced form $\left(m S E F_{I R}\right)$ could not activate $F L C$ expression and hence failed to delay flowering under LD and SD conditions (Fig. 5b and e; Fig. 6; Additional file 11: Table S7; Additional file 12: Table S8).

These results reveal that the derepression of $F L C$ in skip-1 was partially caused by a deficiency in the splicing of $S E F$, which is the major target through which SKIP regulates $F L C$ expression (Figs. 5 and 6). 


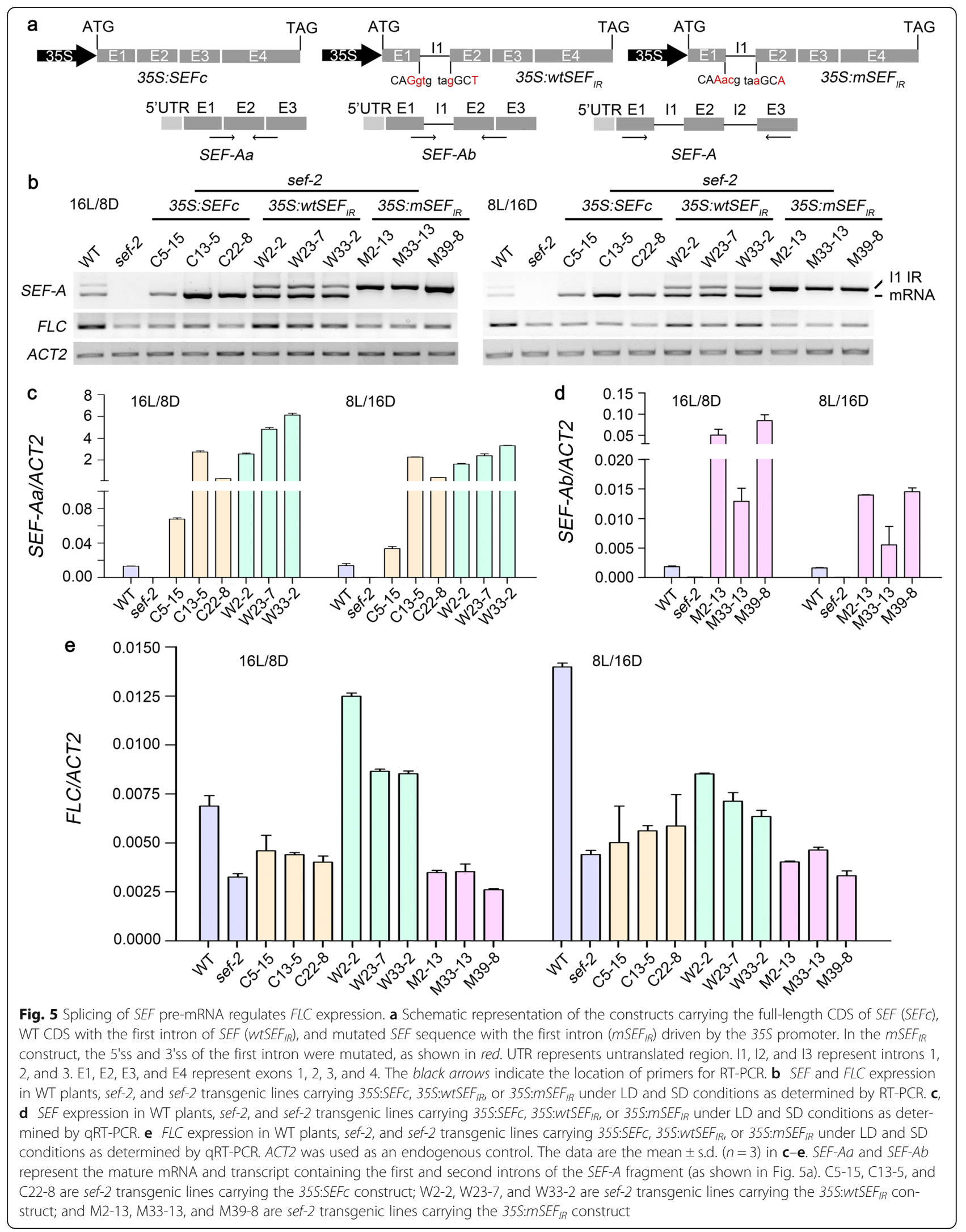




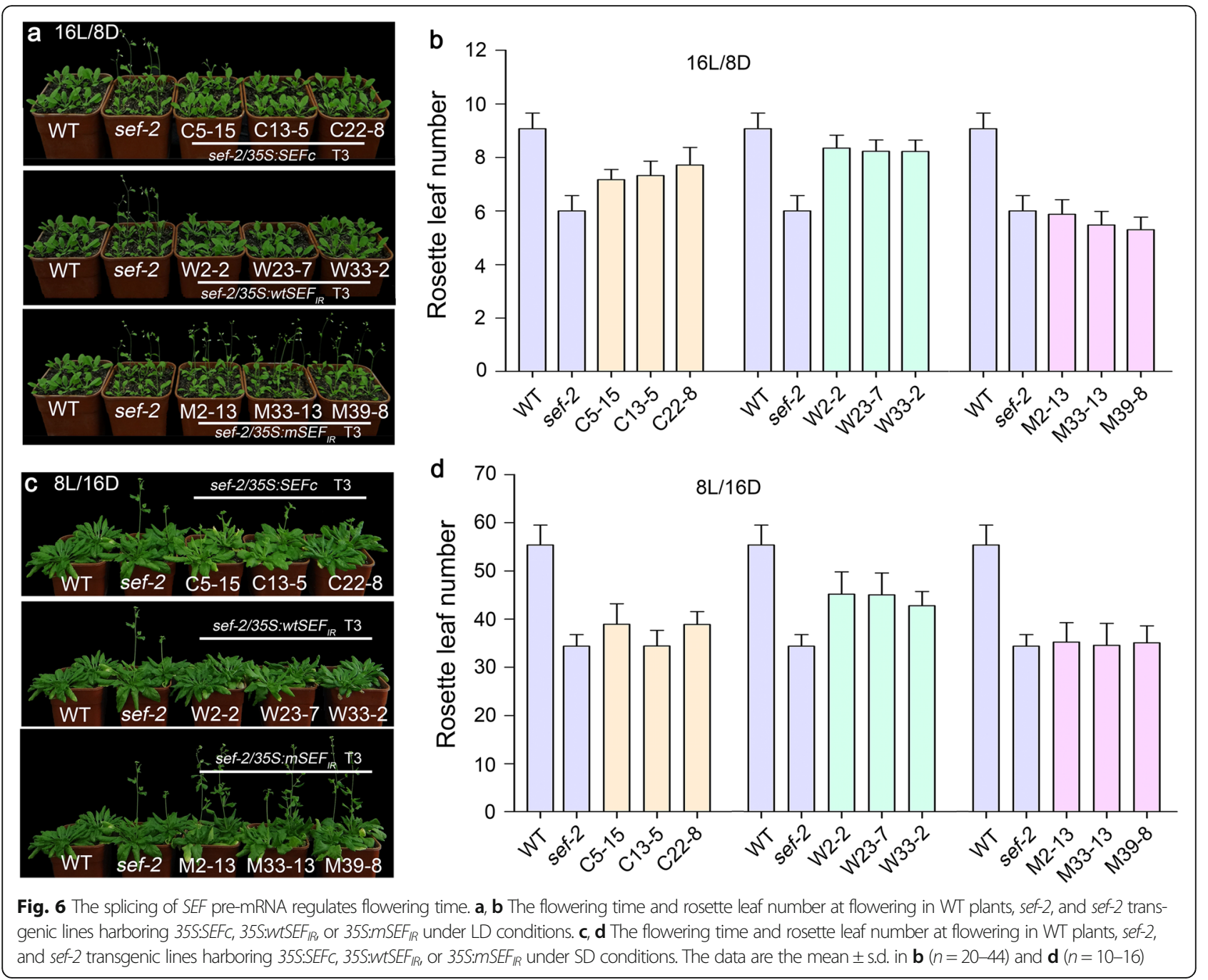

SKIP is associated with SEF pre-mRNA

SKIP is localized to the nucleus [40, 55] (Additional file 13: Figure S4). During pre-mRNA splicing, the spliceosome is recruited to pre-mRNAs. Therefore, we examined whether the SKIP-containing spliceosome is associated with SEF premRNA in vivo by RNA immunoprecipitation (RNA-IP).

C12-1, a transgenic line expressing a green fluorescent protein (GFP)-SKIP fusion protein (from $S K I P: G F P-S K I P)$, recovered the early flowering phenotype of the skip-1, indicating that SKIP was functional in this line (Fig. 7a). We next used a commercial antibody against GFP to immunoprecipitate GFPSKIP. The GFP-SKIP immunoprecipitates were then reverse-transcribed into $\mathrm{CDNA}$ and amplified by PCR with SEF-specific primers. Four sets of samples were prepared: no immunoprecipitation (Input; positive control), immunoprecipitation without anti-GFP antibodies (NA-IP; negative control), and PCR following RNA-IP against GFP with (RT+) or without (RT-) reverse transcription (Fig. $7 \mathrm{~b}$ ).
SEF pre-mRNA was detected in the Input and RT+ samples from line $\mathrm{C} 12-1$ and confirmed by sequencing (Fig. 7b). These results suggest a role for the SKIP-containing spliceosome in the splicing of $S E F$ pre-mRNA.

\section{SKIP activates $F L C$ by regulating the splicing of SEF pre-} mRNA by replacing $\mathrm{H} 2 \mathrm{~A}$ with $\mathrm{H} 2 \mathrm{~A} . \mathrm{Z}$ at $F L C$ chromatin SEF is a component of the SWR1-C, which is involved in the deposition of H2A.Z to target chromatin to activate gene expression [20]. To determine whether the reduced expression of SEF in skip-1 plants influences the deposition of H2A.Z on a global scale, nucleoproteins were extracted from WT, skip-1, sef-2, and arp6-5 plants and Western blot analyses were performed using antiH2A.Z antibodies. Compared to the WT, the H2A.Z enrichment on a global scale was significantly reduced by skip-1, sef-2, and arp6-5 mutations, indicating that SKIP may be involved in chromatin remodeling through the splicing of SEF in vivo (Fig. 7c). 


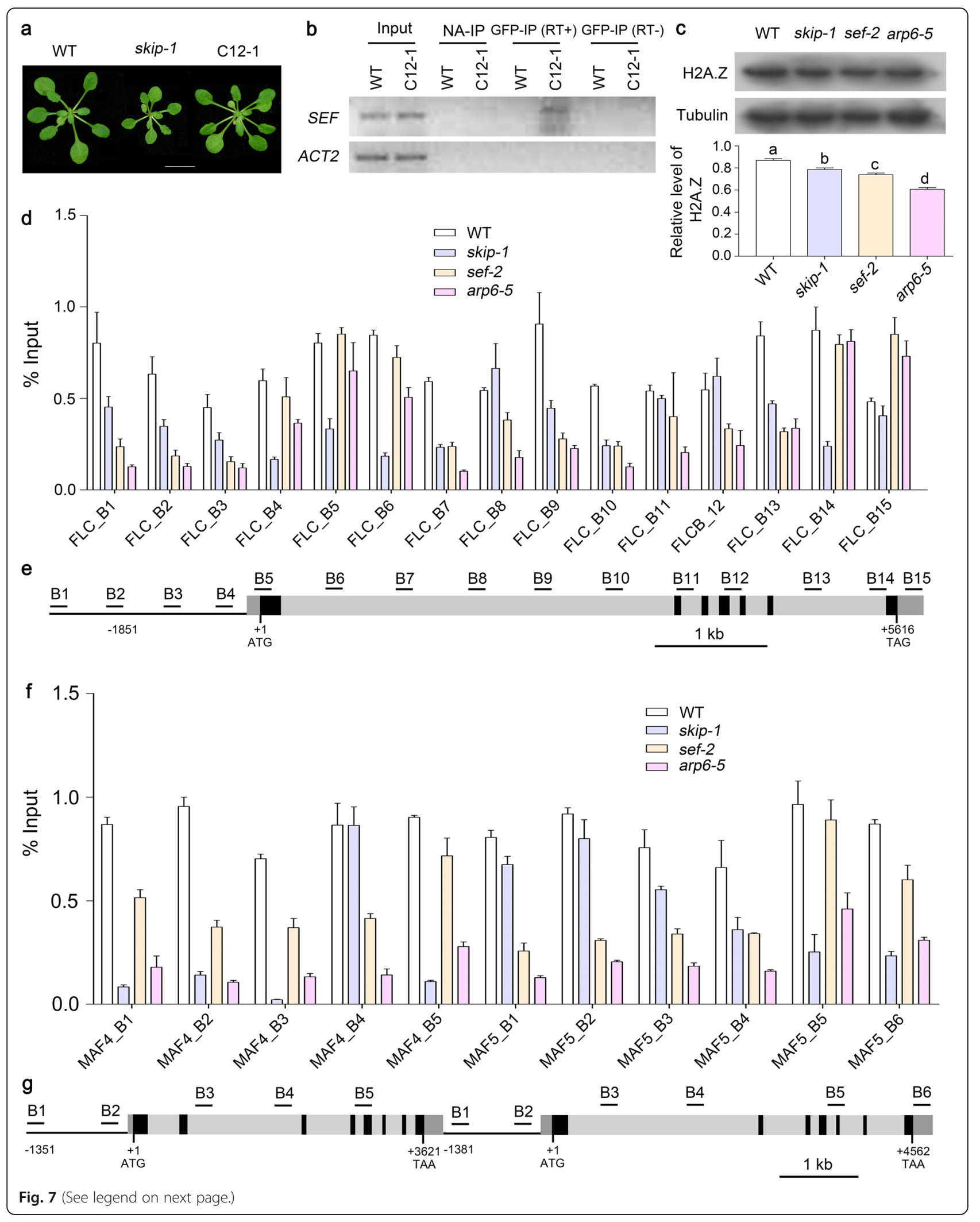




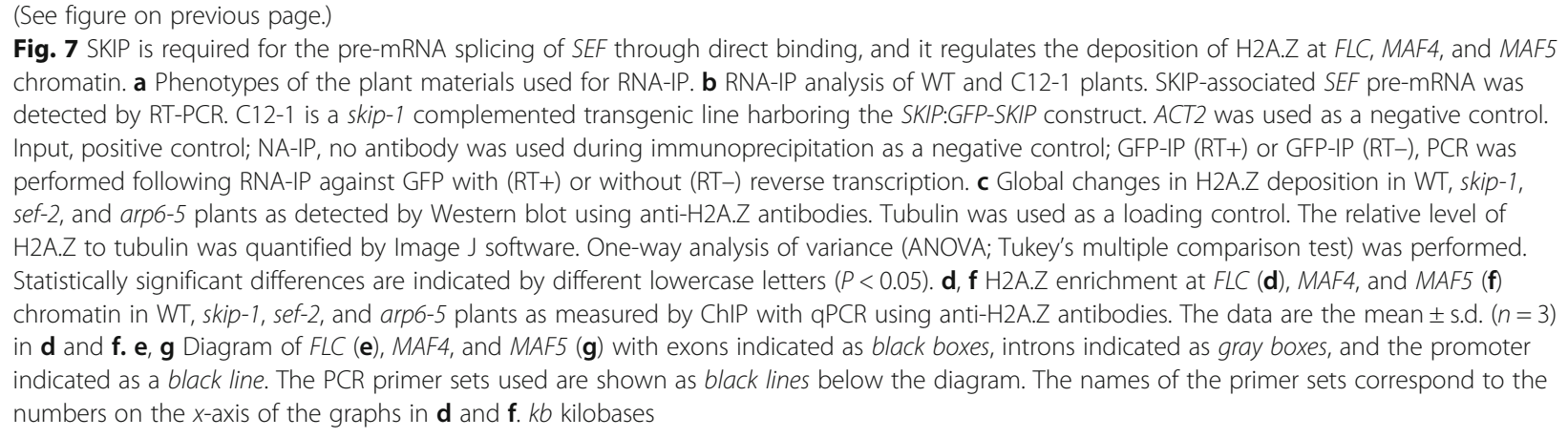

To verify whether the reduced transcript level of SEF in skip-1 affects the deposition of H2A.Z at FLC, we performed a chromatin immunoprecipitation (ChIP) assay to determine the level of H2A.Z across the entire FLC locus (Fig. 7d and e). In the WT, H2A.Z was predominantly enriched around the translation start site and first intron (regions B5, B6, and B9), stop site, and 3' untranslated region (regions B13, B14, and B15), consistent with previous data [21] (Fig. 7d). The abundance of H2A.Z across FLC chromatin was lower in skip-1 than in the WT, except in regions B8, B11, and B12 (Fig. 7d and e).

To analyze whether the reduced level of SEF in skip-1 was responsible for the down-regulation of MAF4 and $M A F 5$, the abundance of H2A.Z across MAF4 and MAF5 was examined in WT, skip-1, sef-2, and arp6-5 plants. The H2A.Z levels across most regions of MAF4 and MAF5 were obviously decreased in skip-1 (Fig. $7 \mathrm{f}$ and g).

These results indicate that the reduced expression of SEF in skip-1 decreased the deposition of H2A.Z at FLC, $M A F 4$, and MAF5 in vivo to suppress their expression and promote flowering (Fig. $7 \mathrm{~d}$ and $\mathrm{f}$ ).

\section{Discussion}

RNA splicing is an essential posttranscriptional process that controls gene expression and increases transcriptomic and proteomic diversity in eukaryotes. The accuracy and efficiency of pre-mRNA splicing, controlled by cis-acting elements and trans-acting factors, play important roles in regulating the expression and normal cellular function of genes [26]. The identification of splicing factors is a key step in dissecting the posttranscriptional regulation of plant development. SKIP, an SNW domain-containing protein, has been reported to be a splicing factor [40]. In this study, the mechanisms whereby SKIP controls flowering time through the alternative splicing were investigated.

\section{SKIP is essential for normal plant development}

According to the present and previous studies, SKIP is a nuclear splicing factor that controls the circadian clock through alternative splicing in Arabidopsis [40, 55] (Additional file 13: Figure S4). Mutations in SKIP globally affect pre-mRNA splicing under normal growth conditions [40]. This finding is consistent with the pleiotropic phenotypes of skip-1 observed in this study. The loss-of-function skip-1 mutant confers early flowering phenotype under LD and SD conditions, which is consistent with the previous results [40, 64] (Fig. 1a-d, Additional files 1 and 2: Tables S1 and S2). In addition, the skip-1 mutant exhibits multiple developmental defects, including short roots, stamens, pistils, and siliques, and small flowers, sepals, and petals, indicating that SKIP plays essential roles in plant development (Fig. 1e-m; Additional file 3: Table S3). However, the mechanisms of SKIP that regulate these biological processes remain unknown.

\section{SKIP is involved in the transcriptional activation of FLC and its homologs}

The mutation in skip-1 suppressed FLC, MAF1, $M A F 4$, and MAF5 expression, accelerated flowering by activating the expression of downstream flowering time integrators (including SOC1, FT, and TSF), and promoted early flowering (Fig. 2; Additional file 4: Figure S1). Consistent with this, the inactivation of $F L C$ in skip-1 partially recovered the late flowering phenotype of the $F L C$-activated mutants $F R I$, fve, and flk (Fig. 3a; Additional file 5: Table S4). Overexpression of $F L C$ rescued the early flowering phenotype of skip-1 (Fig. 3b and c; Additional file 6: Table S5 and Additional file 7: Table S6). These results provide solid evidence that the suppression of $F L C$ expression is responsible for the early flowering phenotype of skip-1, suggesting that SKIP is required for the activation of FLC expression. However, the results of our pre-mRNA splicing assay and the previous report show that SKIP did not affect the splicing of $F L C$ pre-mRNA, implying that SKIP indirectly regulates $F L C$ expression to control flowering [64] (Additional file 8: Figure S2a).

SKIP links the posttranscriptional regulation of SWR1-C to activation of $F L C$ and its homologs

SKIP regulates the splicing of SEF pre-mRNA to control $F L C, M A F 4$, and MAF5 expression and flowering time. 
The skip-1 mutation did not impact the levels of mature mRNA produced from genes encoding FLC suppressors and activators of the autonomous and vernalization pathways [24], except for SEF (Additional file 8: Figure S2b-d).

SEF is a component of the SWR1-C, which exchanges histone $\mathrm{H} 2 \mathrm{~A}$ for H2A.Z, producing variant nucleosomes. The SWR1-C is required for H2A.Z deposition at three loci: FLC, MAF4, and MAF5. The enrichment of H2A.Z deposition at FLC, MAF4, and MAF5 chromatin promotes their transcription and delays flowering [21]. However, the regulatory mechanisms (especially posttranscriptional regulation) affecting the functions of the SWR1-C are unknown. In this study, we found that SKIP bound SEF pre-mRNA and regulated its splicing (Fig. 4 and Fig. 7b; Additional file 8: Figure S2). Our results show that the skip-1 mutation confers defects in SEF pre-mRNA splicing, leading to a reduced level of mature SEF mRNA and elevated levels of alternatively spliced $S E F$ isoforms due to intron retention (Fig. 3; Additional file 8: Figure S2d; Additional file 10: Figure S3). These isoforms of SEF do not function as mature SEF mRNAs because they cannot complement the early flowering defects in $s e f-2$. Our findings show that the reduced level of mature $S E F$ mRNA caused by abnormal splicing in skip-1 inactivated the expression of FLC, MAF4, and $M A F 5$ and accelerated flowering. These results are consistent with studies showing that mutations in PIE1, ARP6, and SEF (i.e., SWR1-C component genes) conferred early flowering phenotypes in Arabidopsis by silencing FLC, MAF4, and MAF5 expression [19, 20, 25, 65, 66]. We were unable to produce a skip-1/sef-2 double mutant because of lethality, indicating that SKIP and SEF are crucial for normal plant development.

In mammals, SKIP acts as a splicing factor and transcriptional co-regulator by interacting with other proteins $[48,49]$. That is the case for the ortholog of SKIP in Arabidopsis. SKIP has also been demonstrated to regulate the expression of $F L C$ and MAFs by interacting with ELF7, a component of the PAF1 complex [64]. The expression of FLC, MAF1, and MAF4 in skip-1 was significantly lower than that in sef-2, which suggests that besides SEF, other regulators, such as ELF7, exist in skip-1 to control the expression of FLC, MAF1, and MAF4 (Additional file 14: Figure S5; Additional file 9: Figure S6c and e). These results reveal that SKIP plays dual roles, acting as splicing factor and transcriptional co-activator, in regulating the expression of $F L C$ and MAFs to control flowering time in Arabidopsis.

The expression of MAF1 in the sef-2 mutant is similar to that in the WT, but significantly higher than that in the skip-1 mutant; however, the splicing isoforms of MAF1 in the skip-1 mutant is higher than that in the WT (Additional file 9: Figure S6a and b). These results indicate that SKIP directly regulates the expression of MAF1 through alternative splicing and the PAF1 complex [64].

\section{SKIP regulates the H2A.Z enrichment at the chromatin of $F L C$ and its homologs to delay flowering through the splicing of SEF pre-mRNA}

Epigenetic modifications, including DNA methylation, histone methylation, acetylation, monoubiquitylation, and chromatin remodeling, of $F L C$ and MAF have been extensively explored [2]. Previous studies showed reduced deposition of H2A.Z at FLC, MAF4, and MAF5 in arp6-1 and pie1-5, causing chromatin configuration changes and the suppression of these genes [21]. In the present study, we found that H2A.Z enrichment at FLC, $M A F 4$, and MAF5 was decreased in sef-2 plants. Similarly, H2A.Z enrichment at FLC, MAF4, and MAF5 was down-regulated by the skip-1 mutation, resulting in the inactivation of their expression and the promotion of flowering in skip-1 plants (Fig. $7 \mathrm{~d}$ and f). Our findings reveal a novel mechanism whereby SKIP controls flowering time through pre-mRNA splicing and posttranscriptional regulation of the SWR1-C via ATP-dependent chromatin remodeling processes (Fig. 8). SKIP is required for the alternative splicing of the $S E F$ pre-mRNA; the splicing of $S E F$ pre-mRNA affects the deposition of H2A.Z at FLC, MAF4, and MAF5 chromatin; H2A.Z deposition activates the expression of these genes to delay flowering in Arabidopsis.

It should be indicated that the levels of mature SEF mRNA and presumably its protein were reduced through alternative splicing but they were not knocked out in skip-1 (e.g., in the sef-2 mutant). It is reasonable to expect that the deposition of H2A.Z in the skip-1 mutant would be intermediate between WT and sef-2; however, the level of H2A.Z at some regions of MAF4 chromatin in skip-1 was lower than that in sef-2 mutant. It is possible that SEF targets substrates with differential affinities or that other unknown factors regulating the deposition of H2A.Z were inactivated in skip-1. This will be confirmed in future experiments.

\section{Conclusions}

Our study reveals the regulatory roles of SKIP in flowering time control of Arabidopsis. SKIP is a splicing factor. The skip-1 mutant exhibits an early flowering phenotype, indicating that SKIP is a suppressor of flowering time. SKIP promotes the expression of floral repressors, including FLC, MAF1, MAF4, and MAF5, and delays flowering time through regulating the premRNA splicing of SEF. SKIP binds to the pre-mRNA of $S E F$ to control its splicing and activates its expression. The elevated expression of SEF by SKIP accelerates the substitution of H2A by H2A.Z at FLC, MAF4, 


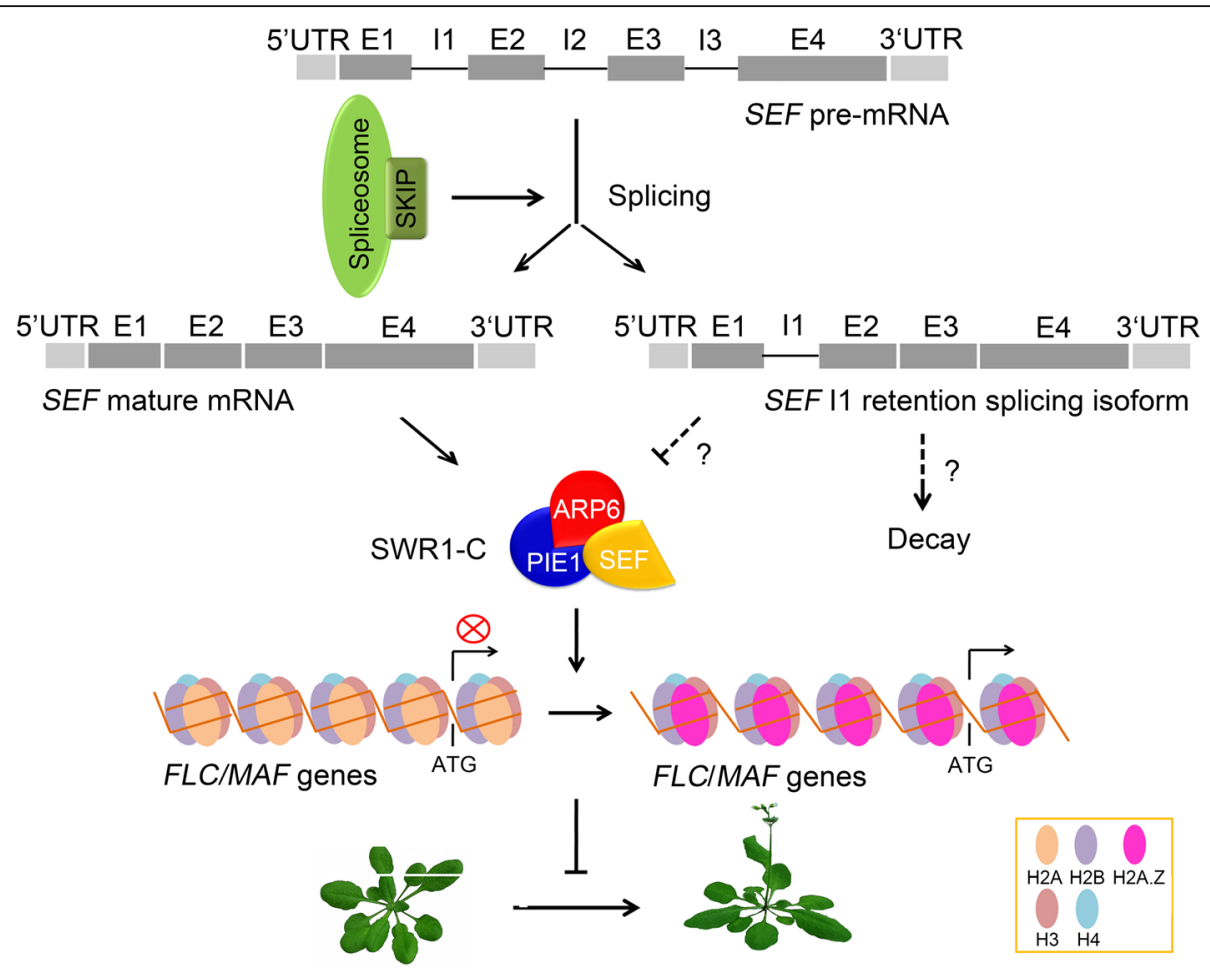

Fig. 8 A model illustrating that SKIP is required for the pre-mRNA splicing of SEF to activate the expression of FLC and MAFs and delay flowering in Arabidopsis. In this model, SKIP, a spliceosome component, regulates the pre-mRNA splicing of SEF, which is integrated into the ATP-dependent SWR1-C. The SWR1-C regulates the substitution of H2A by H2A.Z at FLC and MAF chromatin, leading to increased FLC/MAF expression and delayed flowering in Arabidopsis. The intron 1 retention alternative splicing form of SEF does not function as SEF mature mRNA, which may be decayed through the nonsense-mediated mRNA decay (NMD) or the mechanisms unknown

and MAF5 chromatin, leading to increased FLC, $M A F 4$, and $M A F 5$ expression and delayed flowering time in Arabidopsis.

\section{Methods}

Plant materials and growth conditions

All plant materials used in this study were of Arabidopsis ecotype Col-0. Seeds were sterilized and placed on Murashige and Skoog (MS) medium with $0.3 \%$ agar and $1 \%$ sucrose. After stratification in the dark at $4{ }^{\circ} \mathrm{C}$ for 2 days, the plates were transferred to white light $\left(70 \mu \mathrm{mol} \mathrm{m}{ }^{-2} \mathrm{~s}^{-1}\right)$ in a Percival CU36L5 growth chamber (Percival Scientific, Perry, IA, USA). Plants for flowering time determination were grown under various light-dark photocycles with cool white fluorescent light $\left(100 \mu \mathrm{mol} \mathrm{m}{ }^{-2} \mathrm{~s}^{-1}\right)$ at $22{ }^{\circ} \mathrm{C}$ during the day and $18{ }^{\circ} \mathrm{C}$ at night.

\section{Root elongation and fresh weight assays}

Five-day-old seedlings grown in MS medium were transferred to fresh MS agar medium and allowed to grow for an additional 14 days before being harvested. The root lengths and shoot and root fresh weights were then measured.

\section{Complementation test}

The construction of $p S K I P: S K I P$ and $p S K I P: G F P-S K I P$ plasmids were described in our previous report [40]. The resulting $p S K I P: S K I P$ and $p S K I P: G F P-S K I P$ plasmids were introduced into skip-1 by Agrobacterium-mediated transformation [67]. Flowering time was examined in T3 transgenic lines (SKIP:SKIP/skip-1). Complemented T3 lines (SKIP:GFP-SKIP/skip-1) were used in RNA-IP.

To produce the 35S:FLC construct, the 591-bp CDS of FLC was amplified and cloned into pCambia1300 under the control of the $35 S$ constitutive promoter. The resulting construct was transformed into skip-1 plants via the Agrobacterium-mediated floral dip method [67]. Transformants were selected on MS medium containing hygromycin. Single insertion lines were selected based on the segregation of antibiotic resistance. Flowering time and FLC mRNA enrichment were examined in T3 transgenic lines.

To produce 35:SEFc, 35S: $w t S E F_{I R}$, and 35S: $m S E F_{I R}$, the 516-bp CDS of $S E F(S E F c)$, the $S E F$ CDS plus the first intron (594 bp; $w t S E F_{I R}$ ), and a mutated version of $S E F$ with the first intron that contained an altered 5 'ss and 3'ss (594 bp; $m S E F_{I R}$ ) were amplified and cloned into pCambia1300 under the control of the $35 S$ promoter. Next, the constructs were transformed into skip-1 via the Agrobacterium-mediated floral dip method [67]. 
Transformants were selected on MS medium containing hygromycin. Single insertion lines were selected based on the segregation of antibiotic resistance. Flowering time and the expression of $S E F$ and $F L C$ were examined in T3 transgenic lines.

\section{Gene expression assays}

For RT-PCR and qRT-PCR, total RNA was extracted from 10-day-old seedlings using Takara RNAiso Plus (Takara Bio Inc., Otsu, Japan). After RNase-free DNase I (RQ1 RNase-Free DNase; Promega, Madison, WI, USA) treatment, $3 \mu \mathrm{g}$ of RNA was used for first-strand cDNA synthesis (RevertAid First Strand cDNA Synthesis Kit; Fermentas, Waltham, MA, USA). Takara SYBR Premix Ex Taq (Takara Bio Inc.) and a 7500 Real-Time PCR Instrument (Applied Biosystems, Foster City, CA, USA) were used for qRT-PCR.

Confocal microscopy and subcellular localization analysis Protoplasts isolated from 3- or 4-week-old Arabidopsis leaves grown under $12 \mathrm{~h}$ of light/12 $\mathrm{h}$ of darkness as described by Asai et al. [68] and transiently transformed with SKIP:GFP-SKIP (constructed in pCambia1300) and roots from 7-day-old T3 transgenic seedlings harboring SKIP:GFP-SKIP were used for a subcellular localization analysis. Images were collected using a Zeiss LSM 510 Meta confocal laser scanning microscope (Carl Zeiss, Oberkochen, Germany) as described previously [69].

\section{Western blot}

For immunoblotting, Arabidopsis seedlings were ground to a powder in liquid nitrogen and then homogenized in extraction buffer $(10 \mathrm{mM}$ Tris- $\mathrm{HCl}$ [pH 7.5], $150 \mathrm{mM}$ $\mathrm{NaCl}, 10 \mathrm{mM} \mathrm{MgCl} 2,1 \%$ Nonidet P-40, complete protease inhibitor [Roche, Basel, Switzerland], and $1 \mathrm{mM}$ phenylmethylsulfonyl fluoride). The extracts were then centrifuged, the pellet removed, and the supernatant boiled in 6X SDS sample buffer. The proteins in the samples were separated by $8 \%$ SDS-PAGE, transferred to polyvinylidene difluoride membranes (Millipore, Billerica, MA, USA), and detected using different antibodies. The antibodies used for H2A.Z and tubulin detection were anti-histone H2A.Z antibodies (Abcam Cat. no. ab4174, Bat. No. 185934-1, RRID: AB_304345; Abcam, Cambridge, UK) and anti- $\alpha$-tubulin (Sigma-Aldrich Cat. No. T5168, Bat. No. 072 M4809, RRID: AB_477579; Sigma-Aldrich, St. Louis, MO, USA). The bound antibodies were visualized using Amersham ECL reagents (GE Healthcare, Little Chalfont, UK). The band intensity was analyzed with Image J software.

\section{RNA-IP}

RNA-IP was conducted as described previously [70, 71] with slight modifications. Thirteen-day-old whole seedlings of transgenic complementation lines harboring SKIP:GFPSKIP in a skip-1 background and grown under LD conditions were harvested to detect the association of SKIP with $S E F$ pre-mRNA. After crosslinking in $1 \%$ formaldehyde, pre-immunoprecipitation treatment, and immunoprecipitation with anti-GFP antibodies (Abcam Cat. No. ab290, Bat. No. GR197631-1, RRID: AB_303395), the immunoprecipitation products were eluted with elution buffer. The associated RNAs were quantified by RT-PCR with primer pairs crossing the intron-exon junctions in SEF pre-mRNA after reversal of the crosslinks.

\section{ChIP}

ChIP was performed as described by Gendrel et al. [72] using 13-day-old seedlings grown on MS medium under LD conditions. Anti-H2A.Z antibodies were purchased from Abcam (Abcam Cat. No. ab4174, Bat. No. 1859341, RRID: AB_304345). The primers used for qPCR are provided in Additional file 15: Table S9.

\section{Accession numbers}

Sequence data from this article can be found in the Arabidopsis Genome Initiative database under the following accession numbers: SKIP (At1g77180), FRI (Col-0) (16-bp deletion), fve (SALK_013789.44.25.x), and flk (SALK_001523.29.35.x). These mutants were ordered from the Arabidopsis Biological Resource Center. The sef-2 (CS841940) and arp5-6 (CS872355) mutants were kindly provided by Dr. Ilha Lee in the Laboratory of Plant Developmental Genetics and School of Biological Sciences at Seoul National University in Korea.

\section{Additional files}

Additional file 1: Table S1. Early flowering phenotypes of skip-1 under LD conditions. (DOC $49 \mathrm{~kb}$ )

Additional file 2: Table S2. Early flowering phenotypes of skip-1 under SD conditions. (DOC $37 \mathrm{~kb}$ )

Additional file 3: Table S3. Root length and fresh weight of skip-1 under LD conditions. (DOC $34 \mathrm{~kb}$ )

Additional file 4: Figure S1. SKIP is essential for FT expression, but it is not required for $\mathrm{CO}$ expression. Ten- or 17-day-old seedlings were used for qRT-PCR analysis. a Expression of $C O$ in WT and skip-1 plants under LD and SD conditions. b Diurnal expression of CO in WT and skip-1 plants under SD conditions. c Diurnal expression of FT in WT and skip-1 plants under SD conditions. ACT2 was used as an endogenous control. Three biological replicates were performed with similar results, and the result from one of the experiments is shown. The values are the mean \pm s.d. (TIF $996 \mathrm{~kb}$ )

Additional file 5: Table S4. skip-1 is able to recover the late flowering phenotypes of $F R I$ and fve, and flk mutants under LD conditions. (DOC $43 \mathrm{~kb}$ )

Additional file 6: Table S5. Overexpression of $F L C$ is able to recover the early flowering phenotypes of skip-1 under LD conditions. (DOC $34 \mathrm{~kb}$ )

Additional file 7: Table S6. FLC expression as measured by qRT-PCR in the skip-1 transgenic lines under LD conditions. (DOC $32 \mathrm{~kb}$ ) 
Additional file 8: Figure S2. Identification of factors through which SKIP activates FLC expression. a Measurement of FLC splicing defects in WT plants, skip-1, and the three skip-1 complemented transgenic lines described in Fig. 1. The locations of the primer pairs used to amplify mature FLC mRNA and its alternatively spliced isoforms (upper panel). Scale bar, $1 \mathrm{~kb}$. FLC was divided into two fragments to amplify its alternatively spliced isoforms by semi-RT-PCR under LD and SD conditions (lower panel). b and c Expression of genes encoding FLC transcriptional activators in WT and skip-1 plants as detected by semi-RT-PCR and qRT-PCR. Three biological replicates were performed with similar results, and the result from one of the experiments is shown. The values are the mean \pm s.d. in c. $d$ The expression of genes encoding FLC transcriptional repressors in WT and skip-1 plants as determined by semi-RT-PCR. ACT2 was used as an endogenous control. IR, alternatively spliced isoforms produced by intron retention. (TIF $7388 \mathrm{~kb}$ )

Additional file 9: Figure S6. The expression and alternative splicing of MAF1, MAF4, and MAF5 in skip-1 and sef-2 mutants under LD conditions. a, c, e MAF1, MAF4, and MAF5 expression in WT, skip-1, sef-2, and three of the skip-1 complemented transgenic lines, including L12-9, L29-11, and L30-2, described in Fig. 1 under LD conditions. b, d, f Alternative splicing of MAF1, MAF4, and MAF5 in WT, skip-1, sef-2, and three of the skip-1 complemented transgenic lines, including L12-9, L29-11, and L30-2, described in Fig. 1 under LD conditions. ACTIN 2 (ACT2) was used as an endogenous control. Three technical replicates were performed. The values are the mean \pm s.d. One-way analysis of variance (ANOVA; Tukey's multiple comparison test) was performed for data in $\mathbf{a}, \mathbf{c}$, and $\mathbf{e}$. Statistically significant differences are indicated by different lowercase letters $(P<0.05)$. There are statistically significant differences between all non-identical letters. (TIF $8262 \mathrm{~kb}$ )

Additional file 10: Figure S3. SKIP, a splicing factor, is essential for the splicing of SEF pre-mRNA. a Locations of the primer pairs used to amplify mature SEF mRNA and its alternatively spliced isoforms. SEF-Ba, SEF-Bb, $S E F-B C$, and SEF-Bd represent the mature mRNA, isoform containing the second intron, isoform containing the third intron, and isoform containing the second and third introns of the SEF-B fragment. The black arrows indicate the location of primers. $b$ and $c$ The levels of mature SEF mRNA and alternatively spliced isoforms in WT and skip-1 plants under LD and SD conditions as determined by qRT-PCR. Three technical replicates were performed. The values are the mean \pm s.d. in $b$ and c. (TIF $1341 \mathrm{~kb}$ )

Additional file 11: Table S7. SEF regulates flowering time through alternative splicing under LD conditions. (DOC $38 \mathrm{~kb}$ )

Additional file 12: Table S8. SEF regulates flowering time through alternative splicing under SD conditions. (DOC $40 \mathrm{~kb}$ )

Additional file 13: Figure S4. SKIP is localized to the nucleus to perform its function. a A SKIP construct encoding GFP driven by the native SKIP promoter (SKIP:GFP-SKIP) was transiently expressed in Arabidopsis protoplasts. b Roots of 7-day-old seedlings stably transformed with SKIP:GFP-SKIP. The images were produced by laser scanning confocal microscopy. DAPI 4',6-diamidino-2-phenylindole. Scale bar, $10 \mu \mathrm{m}$ in a and $20 \mu \mathrm{m}$ in b. (TIF $4964 \mathrm{~kb}$ )

Additional file 14: Figure S5. The expression of $F L C$ in WT, skip-1, sef-2, and three of the skip-1 complemented transgenic lines, including L12-9, L29-11, and L30-2, described in Fig. 1 under LD conditions. ACTIN 2 (ACT2) was used as an endogenous control. Three technical replicates were performed. The values are the mean \pm s.d. One-way analysis of variance (ANOVA; Tukey's multiple comparison test) was performed. Statistically significant differences are indicated by different lowercase letters $(P<0.05)$. There are statistically significant differences between al non-identical letters. (TIF $503 \mathrm{~kb}$ )

Additional file 15: Table S9. Primers used in ChIP assays. (DOC $43 \mathrm{~kb}$ )

\section{Abbreviations}

ARP6: Actin-related protein 6; CCA1: Circadian clock-associated 1; CO: CONSTANS; FCA: Flowering time control locus A; FLC: Flowering locus C; FLD: Flowering locus D; FLK: Flowering locus K; FRI: FRIGIDA; FT: Flowering locus T; FTIP1: FT-interacting protein 1; GFP: Green fluorescent protein; LD: Long day; MAF: MADS affecting flowering; PAF1: Polymerase-associated factor 1; PIE1: Photoperiod-independent early flowering 1; PRR7: PSEUDO-
RESPONSE REGULATOR 7; SD: Short day; SEF: Serrated leaves and early flowering; SKIP: Ski-interacting protein; snRNP: Small nuclear ribonucleoprotein particle; SOC1: Suppressor of overexpression of constans 1; SR: Serine/arginine-rich; SWR1-C: SWR1 chromatin remodeling complex; TSF: Twin sister of FT; VIN3: Vernalization insensitive 3; VRN1: Vernalization 1

\section{Acknowledgements}

We thank Dr. Jessica Habashi for her critical reading of the manuscript. We also thank Dr. Fangming Wu, Dr. Ying Cao, and Huamei Wang for their technical assistance with the manuscript. This work was supported by grants from the National Natural Science Foundation of China (NSFC), grant number 31371222, and the Basic Research Fund for Key Laboratory of Education Department of Liaoning Province (grant number LZ2014033).

\section{Availability of data and materials}

All data generated or analyzed during this study are included in this published article and its additional files.

\section{Authors' contributions}

XW designed the study. XW identified the mutant, cloned the gene, and produced the SKIP-related constructs, transgenic lines, and double mutants. ZC and $Z \mathrm{Y}$ analyzed the flowering phenotype. $\mathrm{XW}, \mathrm{ZC}, \mathrm{YH}$, and $\mathrm{WY}$ performed the semi-RT-PCR and GRT-PCR experiments. ZC, YH, WY, and XY produced the SEFrelated constructs and performed the necessary transformations and phenotype analyses. AT performed the Western blot, RNA-IP assays, ChIP experiments, and associated analyses. XW and ZC performed the flowering time-related gene pre-mRNA splicing assays. XW, ZC, and ZY analyzed the results and prepared the figures and tables. XW wrote the paper. All authors discussed the results and commented on the manuscript. All authors read and approved the final manuscript.

\section{Competing interests}

The authors declare that they have no competing interests.

\section{Publisher's Note}

Springer Nature remains neutral with regard to jurisdictional claims in published maps and institutional affiliations.

\section{Received: 19 May 2017 Accepted: 25 August 2017}

Published online: 11 September 2017

\section{References}

1. He Y, Amasino RM. Role of chromatin modification in flowering-time control. Trends Plant Sci. 2005:10(1):30-5.

2. Song $Y$ H, Ito $S$, Imaizumi T. Flowering time regulation: photoperiod- and temperature-sensing in leaves. Trends Plant Sci. 2013;18(10):575-83.

3. Michaels SD, Amasino RM. FLOWERING LOCUS C encodes a novel MADS domain protein that acts as a repressor of flowering. Plant Cell. 1999;11(5):949-56

4. Ratcliffe OJ, Riechmann JL. Arabidopsis transcription factors and the regulation of flowering time: a genomic perspective. Curr Issues Mol Biol. 2002:4(3):77-91.

5. Scortecci KC, Michaels SD, Amasino RM. Identification of a MADS-box gene, FLOWERING LOCUS M, that represses flowering. Plant J. 2001;26(2):229-36.

6. Kim DH, Doyle MR, Sung S, Amasino RM. Vernalization: winter and the timing of flowering in plants. Annu Rev Cell Dev Biol. 2009;25:277-99.

7. Marquardt S, Boss PK, Hadfield J, Dean C. Additional targets of the Arabidopsis autonomous pathway members. FCA FY J Exp Bot. 2006;57(13): 3379-86.

8. Manzano D, Marquardt S, Jones AM, Baurle I, Liu F, Dean C. Altered interactions within FY/AtCPSF complexes required for Arabidopsis FCA-mediated chromatin silencing. Proc Natl Acad Sci U S A. 2009;106(21):8772-7.

9. Swiezewski S, Liu F, Magusin A, Dean C. Cold-induced silencing by long antisense transcripts of an Arabidopsis Polycomb target. Nature. 2009; 462(7274):799-802.

10. Liu F, Marquardt S, Lister C, Swiezewski S, Dean C. Targeted 3' processing of antisense transcripts triggers Arabidopsis FLC chromatin silencing. Science. 2010;327(5961):94-7.

11. Oh S, Zhang H, Ludwig P, van Nocker S. A mechanism related to the yeast transcriptional regulator Paf1c is required for expression of the Arabidopsis FLC/MAF MADS box gene family. Plant Cell. 2004;16(11):2940-53. 
12. He Y, Doyle MR, Amasino RM. PAF1-complex-mediated histone methylation of FLOWERING LOCUS C chromatin is required for the vernalization-responsive, winter-annual habit in Arabidopsis. Genes Dev. 2004;18(22):2774-84.

13. Cao $Y$, Dai $Y$, Cui $S, M a L$. Histone H2B monoubiquitination in the chromatin of FLOWERING LOCUS C regulates flowering time in Arabidopsis. Plant Cell. 2008;20(10):2586-602.

14. Xu L, Menard R, Berr A, Fuchs J, Cognat V, Meyer D, et al. The E2 ubiquitinconjugating enzymes, AtUBC1 and AtUBC2, play redundant roles and are involved in activation of FLC expression and repression of flowering in Arabidopsis thaliana. Plant J. 2009;57(2):279-88.

15. Zhao Z, Yu Y, Meyer D, Wu C, Shen WH. Prevention of early flowering by expression of FLOWERING LOCUS C requires methylation of histone H3 K36. Nat Cell Biol. 2005;7(12):1256-60.

16. Kim SY, He Y, Jacob Y, Noh YS, Michaels S, Amasino R. Establishment of the vernalization-responsive, winter-annual habit in Arabidopsis requires a putative histone H3 methyl transferase. Plant Cell. 2005; 17(12):3301-10.

17. Pien S, Fleury D, Mylne JS, Crevillen P, Inze D, Avramova Z, et al. ARABIDOPSIS TRITHORAX1 dynamically regulates FLOWERING LOCUS C activation via histone 3 lysine 4 trimethylation. Plant Cell. 2008;20(3):580-8.

18. Saleh A, Alvarez-Venegas R, Yilmaz M, Le O, Hou G, Sadder M, et al. The highly similar Arabidopsis homologs of trithorax ATX1 and ATX2 encode proteins with divergent biochemical functions. Plant Cell. 2008; 20(3):568-79.

19. Noh YS, Amasino RM. PIE1, an ISWI family gene, is required for FLC activation and floral repression in Arabidopsis. Plant Cell. 2003;15(7):1671-82.

20. March-Diaz R, Garcia-Dominguez M, Florencio FJ, Reyes JC. SEF, a new protein required for flowering repression in Arabidopsis, interacts with PIE1 and ARP6. Plant Physiol. 2007;143(2):893-901.

21. Deal RB, Topp CN, McKinney EC, Meagher RB. Repression of flowering in Arabidopsis requires activation of FLOWERING LOCUS C expression by the histone variant H2A.Z. Plant Cell. 2007;19(1):74-83.

22. Johanson U, West J, Lister C, Michaels S, Amasino R, Dean C. Molecular analysis of FRIGIDA, a major determinant of natural variation in Arabidopsis flowering time. Science. 2000;290(5490):344-7.

23. Lempe J, Balasubramanian S, Sureshkumar S, Singh A, Schmid M, Weigel D. Diversity of flowering responses in wild Arabidopsis thaliana strains. PLoS Genet. 2005;1(1):109-18.

24. Crevillen P, Dean C. Regulation of the floral repressor gene FLC: the complexity of transcription in a chromatin context. Curr Opin Plant Biol. 2011;14(1):38-44

25. Choi K, Park C, Lee J, Oh M, Noh B, Lee I. Arabidopsis homologs of components of the SWR1 complex regulate flowering and plant development. Development. 2007;134(10):1931-41.

26. Braunschweig U, Gueroussov S, Plocik AM, Graveley BR, Blencowe BJ. Dynamic integration of splicing within gene regulatory pathways. Cell. 2013;152(6):1252-69.

27. Moore MJ, Proudfoot NJ. Pre-mRNA processing reaches back to transcription and ahead to translation. Cell. 2009:136(4):688-700.

28. Turunen JJ, Niemela EH, Verma B, Frilander MJ. The significant other: splicing by the minor spliceosome. Wiley Interdiscip Rev RNA. 2013;4(1):61-76.

29. Hoskins AA, Moore MJ. The spliceosome: a flexible, reversible macromolecular machine. Trends Biochem Sci. 2012;37(5):179-88.

30. Black DL. Mechanisms of alternative pre-messenger RNA splicing. Annu Rev Biochem. 2003;72:291-336.

31. Reddy AS, Marquez Y, Kalyna M, Barta A. Complexity of the alternative splicing landscape in plants. Plant Cell. 2013;25(10):3657-83.

32. Filichkin SA, Priest HD, Givan SA, Shen R, Bryant DW, Fox SE, et al. Genomewide mapping of alternative splicing in Arabidopsis thaliana. Genome Res. 2010;20(1):45-58.

33. Syed NH, Kalyna M, Marquez Y, Barta A, Brown JW. Alternative splicing in plants-coming of age. Trends Plant Sci. 2012;17(10):616-23.

34. Dinesh-Kumar SP, Baker BJ. Alternatively spliced N resistance gene transcripts: their possible role in tobacco mosaic virus resistance. Proc Nat Acad Sci U S A. 2000;97(4):1908-13.

35. Guan Q, Wu J, Zhang Y, Jiang C, Liu R, Chai $C$, et al. A DEAD box RNA helicase is critical for pre-mRNA splicing, cold-responsive gene regulation, and cold tolerance in Arabidopsis. Plant Cell. 2013;25(1):342-56.

36. Zhan X, Qian B, Cao F, Wu W, Yang L, Guan Q, et al. An Arabidopsis PWI and RRM motif-containing protein is critical for pre-mRNA splicing and ABA responses. Nat Commun. 2015;6:8139.
37. Cui Z, Xu Q, Wang X. Regulation of the circadian clock through pre-mRNA splicing in Arabidopsis. J Exp Bot. 2014;65(8):1973-80.

38. Wang $X$, Ma L. Unraveling the circadian clock in Arabidopsis. Plant Signal Behav. 2013:8(2):e23014.

39. Jones MA, Williams BA, McNicol J, Simpson CG, Brown JW, Harmer SL. Mutation of Arabidopsis spliceosomal timekeeper locus1 causes circadian clock defects. Plant Cell. 2012;24(10):4066-82.

40. Wang $X$, Wu F, Xie Q, Wang H, Wang Y, Yue $Y$, et al. SKIP is a component of the spliceosome linking alternative splicing and the circadian clock in Arabidopsis. Plant Cell. 2012;24(8):3278-95.

41. Sanchez SE, Petrillo E, Beckwith EJ, Zhang X, Rugnone ML, Hernando CE, et al. A methyl transferase links the circadian clock to the regulation of alternative splicing. Nature. 2010;468(7320):112-6.

42. Seo PJ, Park MJ, Lim MH, Kim SG, Lee M, Baldwin IT, et al. A self-regulatory circuit of CIRCADIAN CLOCK-ASSOCIATED1 underlies the circadian clock regulation of temperature responses in Arabidopsis. Plant Cell. 2012;24(6):2427-42.

43. Ohtani M, Demura T, Sugiyama M. Arabidopsis root initiation defective1, a DEAH-box RNA helicase involved in pre-mRNA splicing, is essential for plant development. Plant Cell. 2013;25(6):2056-69.

44. Macknight R, Duroux M, Laurie R, Dijkwel P, Simpson G, Dean C. Functional significance of the alternative transcript processing of the Arabidopsis floral promoter FCA. Plant Cell. 2002;14(4):877-88.

45. Quesada V, Macknight R, Dean C, Simpson GG. Autoregulation of FCA pre-mRNA processing controls Arabidopsis flowering time. EMBO J. 2003;22(12):3142-52.

46. Wu Z, Zhu D, Lin X, Miao J, Gu L, Deng X, et al. RNA binding proteins RZ-1B and RZ-1C play critical roles in regulating pre-mRNA splicing and gene expression during development in Arabidopsis. Plant Cell. 2016;28(1):55-73.

47. Jang YH, Park HY, Lee KC, Thu MP, Kim SK, Suh MC, et al. A homolog of splicing factor SF1 is essential for development and is involved in the alternative splicing of pre-mRNA in Arabidopsis thaliana. Plant $J$. 2014:78(4):591-603.

48. Bres V, Yoshida T, Pickle L, Jones KA. SKIP interacts with c-Myc and Menin to promote HIV-1 Tat transactivation. Mol Cell. 2009;36(1):75-87.

49. Chen $Y$, Zhang $L$, Jones KA. SKIP counteracts p53-mediated apoptosis via selective regulation of p21Cip1 mRNA splicing. Genes Dev. 2011:25(7):701-16.

50. Gahura O, Abrhamova K, Skruzny M, Valentova A, Munzarova V, Folk P, et al. Prp45 affects Prp22 partition in spliceosomal complexes and splicing efficiency of non-consensus substrates. J Cell Biochem. 2009;106(1):139-51.

51. Bessonov S, Anokhina M, Will CL, Urlaub H, Luhrmann R. Isolation of an active step I spliceosome and composition of its RNP core. Nature. 2008; 452(7189):846-50

52. Figueroa JD, Hayman MJ. The human Ski-interacting protein functionally substitutes for the yeast PRP45 gene. Biochem Biophys Res Commun. 2004; 319(4):1105-9.

53. Hou X, Xie K, Yao J, Qi Z, Xiong L. A homolog of human ski-interacting protein in rice positively regulates cell viability and stress tolerance. Proc Natl Acad Sci U S A. 2009;106(15):6410-5.

54. Zhang $X$, Min JH, Huang $P$, Chung JS, Lee KH, Kim CS. AtSKIP functions as a mediator between cytokinin and light signaling pathway in Arabidopsis thaliana. Plant Cell Rep. 2014;33(3):401-9.

55. Lim GH, Zhang X, Chung MS, Lee DJ, Woo YM, Cheong HS, et al. A putative novel transcription factor, AtSKIP, is involved in abscisic acid signalling and confers salt and osmotic tolerance in Arabidopsis. New Phytol. 2010;185(1):103-13.

56. Song YH, Shim JS, Kinmonth-Schultz HA, Imaizumi T. Photoperiodic flowering: time measurement mechanisms in leaves. Annu Rev Plant Biol. 2015:66:441-64

57. Michaels SD, Himelblau E, Kim SY, Schomburg FM, Amasino RM. Integration of flowering signals in winter-annual Arabidopsis. Plant Physiol. 2005;137(1):149-56.

58. Yamaguchi A, Kobayashi Y, Goto K, Abe M, Araki T. TWIN SISTER OF FT (TSF) acts as a floral pathway integrator redundantly with FT. Plant Cell Physiol. 2005:46(8):1175-89.

59. Abe M, Kobayashi $Y$, Yamamoto S, Daimon $Y$, Yamaguchi A, Ikeda $Y$, et al. FD, a bZIP protein mediating signals from the floral pathway integrator FT at the shoot apex. Science. 2005;309(5737):1052-6.

60. Wigge PA, Kim MC, Jaeger KE, Busch W, Schmid M, Lohmann JU, et al. Integration of spatial and temporal information during floral induction in Arabidopsis. Science. 2005;309(5737):1056-9.

61. Ausin I, Alonso-Blanco C, Jarillo JA, Ruiz-Garcia L, Martinez-Zapater JM. Regulation of flowering time by FVE, a retinoblastoma-associated protein. Nat Genet. 2004;36(2):162-6. 
62. Mockler TC, Yu X, Shalitin D, Parikh D, Michael TP, Liou J, et al. Regulation of flowering time in Arabidopsis by $\mathrm{K}$ homology domain proteins. Proc Natl Acad Sci U S A. 2004;101(34):12759-64.

63. Lim MH, Kim J, Kim YS, Chung KS, Seo YH, Lee I, et al. A new Arabidopsis gene, FLK, encodes an RNA binding protein with $K$ homology motifs and regulates flowering time via FLOWERING LOCUS C. Plant Cell. 2004;16(3):731-40.

64. Cao Y, Wen L, Wang Z, Ma L. SKIP interacts with the Paf1 complex to regulate flowering via the activation of FLC transcription in Arabidopsis. Mol Plant. 2015;8(12):1816-9.

65. Choi K, Kim S, Kim SY, Kim M, Hyun Y, Lee H, et al. SUPPRESSOR OF FRIGIDA3 encodes a nuclear ACTIN-RELATED PROTEIN6 required for floral repression in Arabidopsis. Plant Cell. 2005;17(10):2647-60.

66. Martin-Trillo M, Lazaro A, Poethig RS, Gomez-Mena C, Pineiro MA, MartinezZapater JM, et al. EARLY IN SHORT DAYS 1 (ESD1) encodes ACTIN-RELATED PROTEIN 6 (AtARP6), a putative component of chromatin remodelling complexes that positively regulates FLC accumulation in Arabidopsis. Development. 2006;133(7):1241-52

67. Clough SJ, Bent AF. Floral dip: a simplified method for Agrobacteriummediated transformation of Arabidopsis thaliana. Plant J. 1998;16(6):735-43.

68. Asai T, Tena G, Plotnikova J, Willmann MR, Chiu WL, Gomez-Gomez L, et al. MAP kinase signalling cascade in Arabidopsis innate immunity. Nature. 2002:415(6875):977-83.

69. An H, Roussot C, Suarez-Lopez P, Corbesier L, Vincent C, Pineiro M, et al. CONSTANS acts in the phloem to regulate a systemic signal that induces photoperiodic flowering of Arabidopsis. Development. 2004;131(15):3615-26.

70. Wierzbicki AT, Haag JR, Pikaard CS. Noncoding transcription by RNA polymerase Pol IVb/Pol V mediates transcriptional silencing of overlapping and adjacent genes. Cell. 2008;135(4):635-48.

71. Zheng B, Wang Z, Li S, Yu B, Liu JY, Chen X. Intergenic transcription by RNA polymerase II coordinates Pol IV and Pol V in siRNA-directed transcriptional gene silencing in Arabidopsis. Genes Dev. 2009;23(24):2850-60.

72. Gendrel AV, Lippman Z, Martienssen R, Colot V. Profiling histone modification patterns in plants using genomic tiling microarrays. Nat Methods. 2005;2(3):213-8.

\section{Submit your next manuscript to BioMed Central and we will help you at every step:}

- We accept pre-submission inquiries

- Our selector tool helps you to find the most relevant journal

- We provide round the clock customer support

- Convenient online submission

- Thorough peer review

- Inclusion in PubMed and all major indexing services

- Maximum visibility for your research

Submit your manuscript at www.biomedcentral.com/submit

) Biomed Central 